\title{
Conjunctival myxoma: a case report
}

\author{
JACOB PE'ER, MICHAEL ILSAR, AND AHMED HIDAYAT \\ From the Department of Ophthalmology, Hadassah University Hospital, Jerusalem, Israel
}

SUMmARY A rare case of conjunctival myxoma in an 18-year-old female is reported. Clinically it presented as a painless mass located in the nasal bulbar conjunctiva. It was composed of spindle and stellate shaped cells in a loose mucoid stroma. Some of the cells had intracytoplasmic vacuoles consistent with dilated rough endoplasmic reticulum and/or intranuclear vacuoles of nuclear membrane invaginations. Mast cells were also seen in the stroma. No recurrence has been reported eight months postoperatively.

Myxoma is an uncommon benign connective tissue tumour that may arise from various parts of the body. ${ }^{1-2}$ Myxomas of the ocular adnexa are rare, and only five cases of conjunctival myxoma have been reported. ${ }^{3-7}$ The following report describes a welldocumented case of this rare neoplasm, a conjunctival myxoma, including ultrastructural study.

\section{Case report}

An 18-year-old healthy white female complained of a small lesion in the nasal bulbar conjunctiva of her right eye which had been present for four months. There was no history of trauma. The lesion was painless and did not cause any other symptoms, and the patient sought medical consultation only for cosmetic reasons. Examination of both eyes was unremarkable except for a pinkish glistening 'cystic' tumour in the nasal bulbar conjunctiva of the right eye. The tumour did not invade the limbus (Fig. 1). A similar though smaller tumour was found at the same location in the fellow eye. The tumours and the conjunctiva around them moved freely over the sclera. The patient's complaints, however, were limited to the right eye, and under local anaesthesia the tumour was completely removed. After eight months there was no scar or recurrence, and the tumour of the fellow eye has not grown in size.

\section{PATHOLOGICAL FINDINGS}

The specimen was composed of a well-circumscribed soft mass measuring $10 \times 4 \times 4 \mathrm{~mm}$. It was composed

Correspondence to Jacob' Pe'er, MD, Department of Ophthalmology, Hadassah University Hospital, PO Box 12000, 91120 Jerusalem, Israel. of a main cyst-like structure, whose cut surface appeared myxomatous, and a connective tissue 'tail.' The entire specimen was covered on one side with a pinkish tissue. A prominent blood vessel, apparently the feeding vessel, was seen entering the tumour (Fig. 2).

Microscopic examination revealed under the slightly acanthotic conjunctival epithelium a mass of very loose connective tissue. It was composed of scattered stellate shaped cells with multiple cytoplasmic processes and spindle shaped cells with bipolar cytoplasmic processes. Both types of cells had moderately large hyperchromatic and slightly pleomorphic nuclei, and were embedded in loose mucoid stroma. The stroma contained reticulin

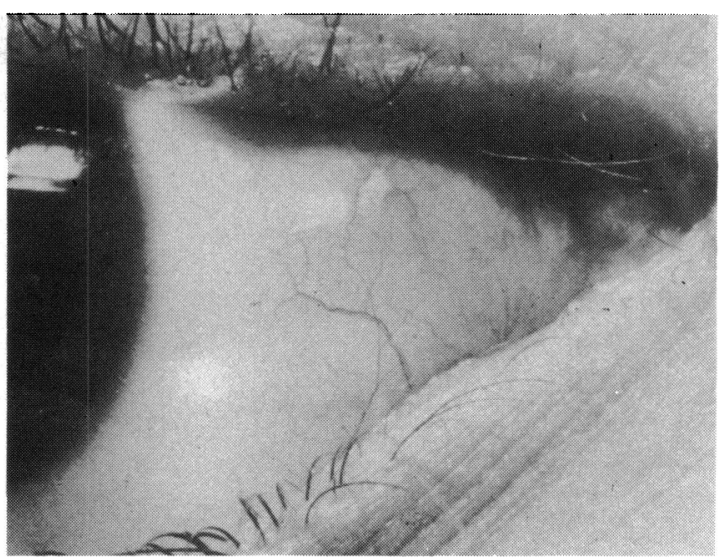

Fig. 1 A shining cystic mass of the nasal bulbar conjunctiva of right eye with prominent blood vessel over it. The mass does not reach the limbus. 


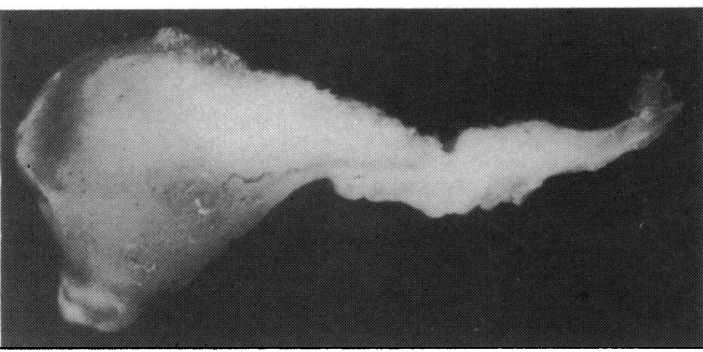

Fig. 2 A well-circumscribed cystic mass with a connective tissue tail. Note the vessel that enters cyst $(\times 6 \cdot 5)$.

fibres and sparse small blood vessels, and collagen fibres that were denser in the periphery (Fig. 3). Some of the tumour cells showed tiny nuclear vacuoles, and some had cytoplasmic vacuoles not impinging on the nucleus (Fig. 4). The vacuoles did not stain with oil-red-o, alcian blue, or PAS stains. There was no mitotic activity. A few mast cells were present within the myxoid stroma. The loose stroma contained abundant hyaluronidase-sensitive mucopolysaccharides. Bodian stain was negative for nerve fibres.

Electron microscopic examination disclosed a piece of tumour tissue composed of predominantly fibroblast-like spindle shaped cells that lacked basement membranes, with prominent rough endoplasmic reticulum and very few other cytoplasmic organelles. Many of the nuclei contained one or two

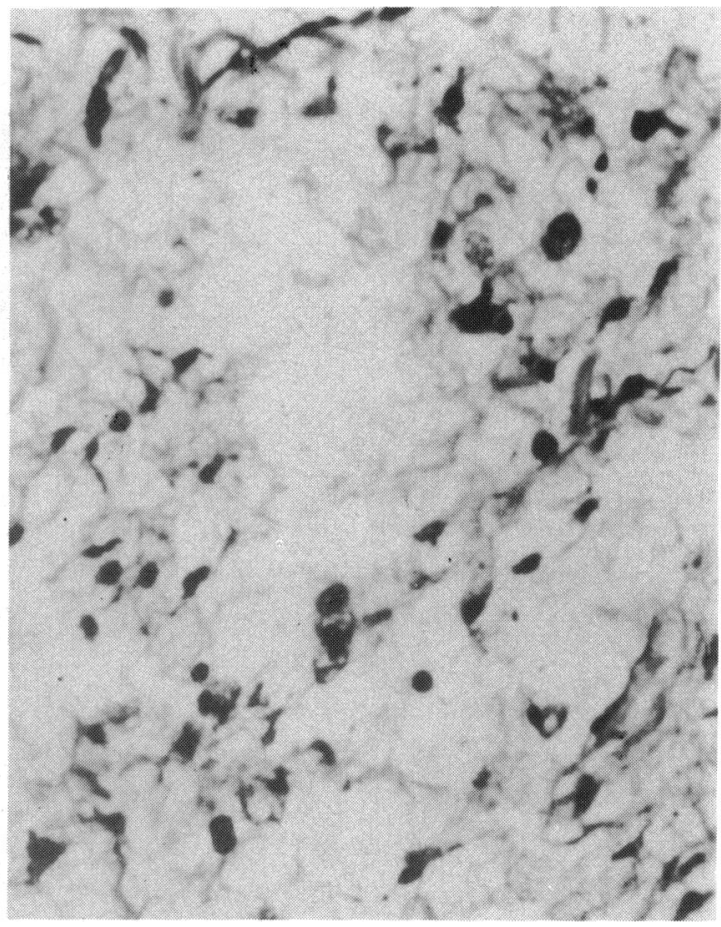

Fig. 4 Stellate and spindle shaped cells with intracranial and intracytoplasmic vacuoles embedded in loose mucoid stroma with reticulum and collagen fibres (Movat pentachrome, $\times 250$ ).

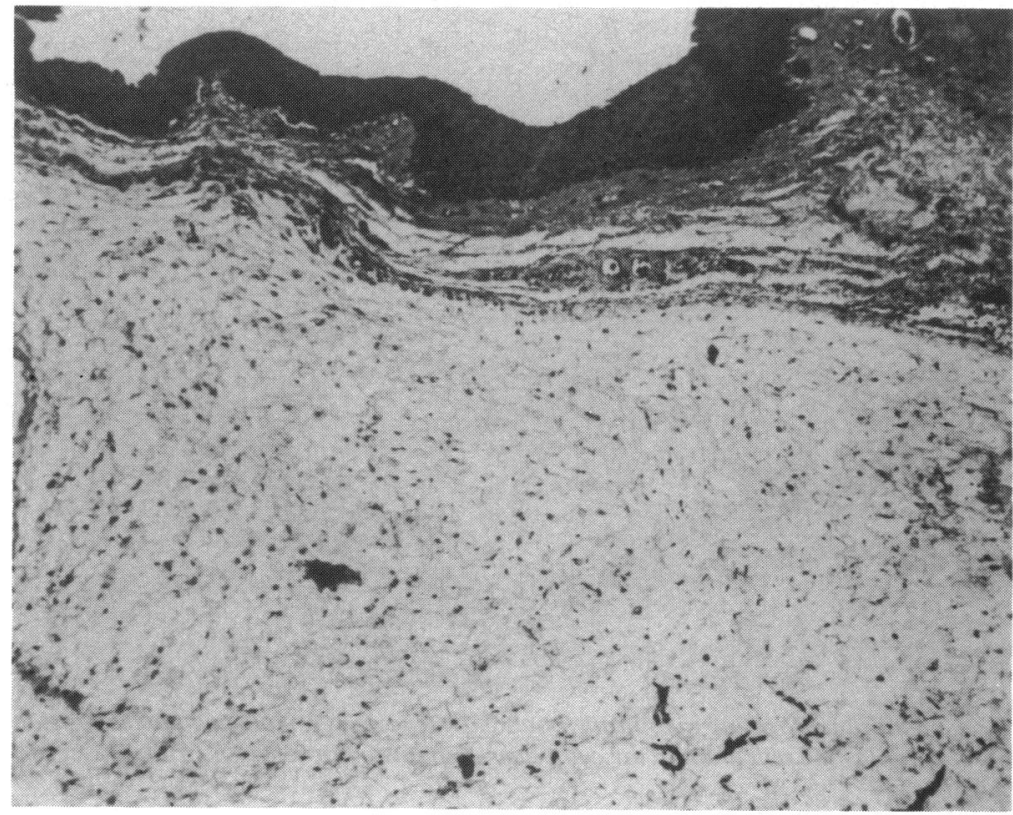

Fig. 3 A loose connective tissue that is denser in its periphery, covered on one side by conjunctival epithelium (Haematoxylin and eosin, $\times 53$ ). 


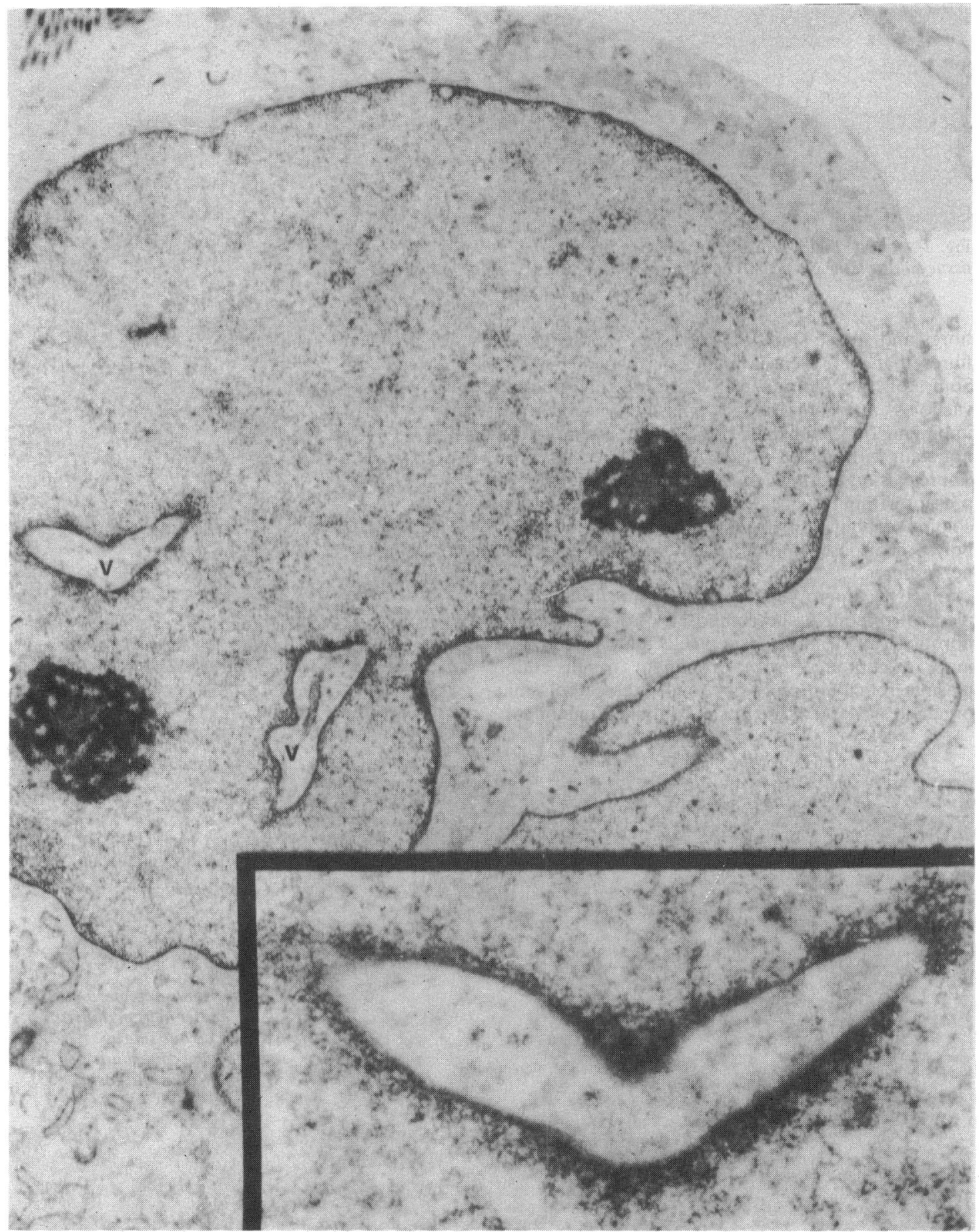

Fig. 5 A cell with infolding of the nuclear membrane, forming membrane bounded vacuoles (v). Note two nucleoli inside the nucleus and prominent rough surfaced endoplasmic reticulum in the cytoplasm (left lower corner) $(\times 12700)$. Insert: higher magnification of a vacuole $(\times 34650)$. 


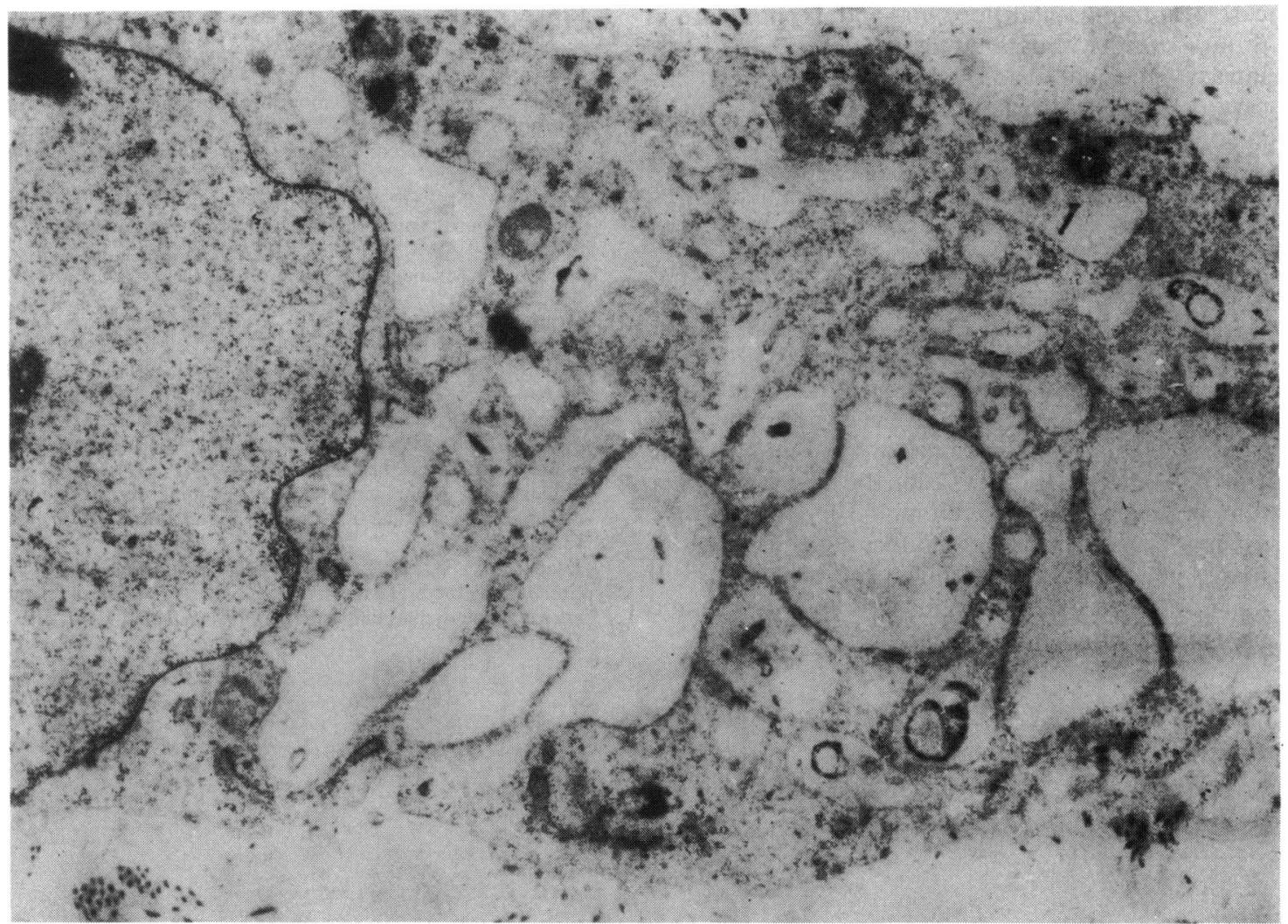

Fig. 6 Extremely dilated cisternae of rough surfaced endoplasmic reticulum. Note some collagen fibres outside the cell $(\times 13500)$.

nucleoli. The extracellular material was amorphic with sparse collagen fibres. Some cells showed infolding of their nuclear membrane that in some sections formed membrane bounded vacuoles (Fig. 5). In some of the cells the cisterna of the rough surfaced endoplasmic reticulum were markedly dilated (Fig. 6).

\section{Discussion}

Pure myxomas have rarely been reported in the ophthalmic literature and only five conjunctival myxomas have been described. Magalif ${ }^{3}$ reported the first case of conjunctival myxoma but without any clinical or histopathological description. Mancione $^{4}$ described the first case of conjunctival myxoma with clinical and histological details. Ffooks ${ }^{5}$ described a case that developed close to a filtration scar, and he considered the lesion to be a complication of trephine operation. The later two well-documented cases reported by Doughman and Wenk $^{6}$ and Stafford 7 appear to be pure myxomas. The age of patients in the previously reported cases was between 49 and 72 years, while our patient was much younger (18 years). The tumour in all cases was well circumscribed, sometimes described as cystic, and were painless. The size of the tumour in all reported cases, including ours, did not exceed $10 \mathrm{~mm}$ in greatest dimension. In two cases ${ }^{67}$ the tumour was temporal to the cornea. Follow-up information in two previous cases and in our case showed no recurrence after 9,64 , and 8 months respectively.

The tumour in our case met the criteria of myxoma. It showed relatively small numbers of stellate and spindle shaped cells embedded in a loose stroma with delicate reticulin fibres and sparse vascular structures and delicate collagen fibres. The stroma contained abundant hyaluronidase sensitive mucopolysaccharides. No mitotic activity was present. ${ }^{12}$ In addition our case presented some other features that have rarely been described in myxomas-the intracytoplasmic and intranuclear vacuoles. These two features were reported in an intramuscular myxoma. ${ }^{8}$ Intranuclear vacuoles alone were described previously in one 
case of intramuscular myxoma ${ }^{9}$ and in one figure in Stout's study ${ }^{2}$ without any textual description, while intracytoplasmic vacuoles alone were described in a case of conjunctival myxoma ${ }^{5}$ and a case of intramuscular myxoma. ${ }^{10}$ The cytoplasmic vacuoles as seen on electron microscopic examination are apparently consistent with markedly dilated rough endoplasmic reticulum, while the intranuclear vacuoles were found to be invaginations of markedly folded nuclear membrane.

Mast cells, demonstrated by Giemsa stain in our case, have not been described previously.

In the differential diagnosis of pure conjunctival myxoma we have to consider mixed myxomas such as fibromyxoma, lipomyxoma, or fibrolipomyxoma, and myxomatous degeneration of tissue or other tumours such as neurofibroma. The degenerative process is sometimes very difficult to prove. It is more important to consider the possibility of malignant tumours such as myxoid liposarcoma and malignant fibrous histiocytoma. ${ }^{1}$

\section{References}

1 Enzinger FM, Weiss SW. Soft tissue tumors. St Louis: Mosby, 1983.

2 Stout AP. Myxoma, the tumor of primitive mesenchyme. Ann Surg 1948; 127: 706-19.

3 Magalif. Myxoma conjunctivae. Klin Monatsbl Augenheilkd 1913; $51: 844$.

4 Mancione DL. Di una rara forma di tumore epibulbare (mixoma puro) sottocongiuntivale. Arch Ottalmol 1914; 21: 300-6.

5 Ffooks OO. Myxoma of the conjunctiva. Br J Ophthalmol 1962; 46: 374-7.

6 Doughman DJ, Wenk RE. Epibulbar myxoma. Am J Ophthalmol 1970; 69: 483-5.

7 Stafford WR. Conjunctival myxoma. Arch Ophthalmol 1971; 85: 443-4.

8 Glazunov MF, Puckov JG. Über die sogenannten Muskelmyxome und Myxosarkome des Menschen mit Zelleinschluessen. Z Krebsforsch 1963; 65: 439-45.

9 Feldman PS. A comparative study including ultrastructure of intramuscular myxoma and myxoid liposarcoma. Cancer 1979; 43: 512-25.

10 Leung TK, Vanzelle JL, Patrirot LM, Lejeune E, Quoneau P. Etude ultrastructurale et cytochinique d'un myxome musculaire associé à une dysplasie fibrense. Ann Anat Pathol (Paris) 1971; 16: $417-28$. 